\section{IJ $\$ E R$}

ISSN: 2149-5939
International Journal of Social Sciences and Education Research

Online, http://dergipark.gov.tr/ijsser

Volume: 3(2), 2017

\title{
Tüketim toplumunda postmodern sanat akımlarının reklamdaki yansımaları
}

\section{The reflections of postmodern art movements on advertising in consumer society}

\author{
Betül Kılıç Taran ${ }^{1}$
}

Received Date: $01 / 09$ / 2016

Accepted Date: 15 / $01 / 2017$

$\ddot{O} z$

Modernizme karşı bir başkaldırı olarak ortaya çıktığı söylenen postmodernizm, tüketim toplumu ile birlikte anılmaya başlanmışsır. Öte yandan, tüketim toplumunda reklam, hedef kitleyi etkileyecek bir strateji olarak, içerisinde postmodern sanat akımlarından ögeler barındırmaya bașlamıștır. Bu çalıșmada, postmodern dönemdeki toplumsal hayatın yeniden inşa edilmesine değinilirken, eş zamanlı olarak oluşturulan yeni bir tüketim kültüründen bahsedilmektedir. Tüketim kültürü, postmodernizm ilişkisi ve postmodern sanatın kuramsal ve sanatsal boyutta gelişimi detaylıca incelenmiştir. Çalışma, postmodernizmin fikir babalarından Jean François Lyotard ve Jean Baudrillard'ın bakış açıları ışı̆̆ında şekillenmiş olup, postmodern sanat akımlarının reklam üzerindeki yansımalarını örneklerle açılklamaktadır. Çalışma kapsamında ele alınan reklam örnekler, postmodern sanat öğeleri (kaos, parçalara ayırma, gündelik hayat, pop, çizgi karakterler, metafor, yorumlanabilir, seri üretim), Lyotard'in postmodern kriterleri (Büyük anlatıların çöküsü - küçük anlatıların tercih edilmesi gerekliliği, büyük alanın parçalara ayrılması, ironi-eleştirel yaklaşım-dolaylı anlatım) ve Baudrillard'in postmodern kriterleri (İsaret ve sembollerle gerçeğin gizlenmesi - yapay dış görünüm, simülakr (taklit) ve simülasyon (benzeşim) - gerçek olanı taklitle benzeştirerek yeni bir imaj oluşturma) bağlamında incelenmiştir. Çalışmanın sonucunda, postmodern sanat akımlarıyla oluşturulan reklamların, postmodern sanatın temel kriterlerini ve dönemin fikir babalarından J. F. Lyotard ve J. Baudrillard'ın öne çıkardığı unsurları fazlasıyla yansıttığı görülmektedir.

Anahtar sözcükler: Tüketim toplumu, postmodernism, postmodern sosyal kuramcılar, postmodern sanat, postmodern reklam,

\begin{abstract}
Postmodernism, which is said to have emerged as a rebellion against modernism, has started to be called with consumer society. On the other hand, advertising in consumer society, strategically gives place to items derived from postmodern art movements in order to appeal target market. This study touches upon how social life is reconstructed in postmodern era and how a new type of consumption culture is created simultaneously. The relation of consumption culture and postmodernism and also development of postmodern art in theoretical and artistic dimensions analyzed in detail. Study refers to the views of Jean François Lyotard and Jean Baudrillard who are pioneers of postmodern thought and explains the reflections of postmodern art movements on advertising with specific examples. The examples of advertisements which were dealt with under the study were examined within the context of postmodern art elements, Lyotard's and Baudrillard's postmodern criterias by simulating the real with the simulacrum. Thus the study observed that the advertisements which are created with postmodern art currents largely reflected main criteria of postmodern art and the elements which were emphasised by J. F. Lyotard and J. Baudrillard, two masterminds of the era.
\end{abstract}

Keywords: Consumer society, postmodernism, postmodern social theorists, postmodern art, postmodern advertising

${ }^{1}$ Arş. Gör., Marmara University, Communication Faculty, Radio, Television and Cinema Department, İstanbul/TURKEY, betul.taran@marmara.edu.tr 
Kılıç Taran, B. (2017). The reflections of postmodern art movements on advertising in consumer society. International Journal of Social Sciences and Education Research, 3(2), 434-447.

\section{Giriş}

1960'lı yıllarda modernizme bir başkaldırı olarak ortaya çıkan postmodernizmde bilginin göreceliliği, salt gerçeklik algısının yıkılması ve yerini yorumlamanın alması postmodern akımın temel yapı taşı olarak görülmektedir. Herhangi bir konuda her bireyin yorumsaması kendi için en doğru olandır. Bu durum kaos ve çatışmayı doğurmaktadır. Çatışma sanatta, edebiyatta, bilim dünyasında, kısaca hayatın her alanına yayılır. Süreç parçalara ayrılmayı, sınırları kaldırmayı beraberinde getirir. Kuramsal çerçeveden bakıldığında da postmodern söylemde üst anlatının yıkıldığı ve tüketim kültürünün getirisi olarak yapay gerçeklik üretiminin vurgulandığı görülmektedir.

Bireyci tavır ve teknolojinin ilerlemesiyle de kültürün hakimiyeti tüketim kültürüne geçmiştir. Tüketimin sağlanabilmesi ise kapitalist düzenin tüketiciler için sembolik ihtiyaçlar yaratmasına bağlıdır. Bu süreç reklamın var olmasıyla işler hale gelmektedir. Dolayısıyla postmodern kültürde reklam önemli bir unsurdur.

Bu bağlamda çalışmada tüketim kültürünün imgesel boyutu olan reklamda rastgele örneklem yöntemiyle seçilen, postmodern sanat akımı kullanılarak tasarlanmış güçlü etki yaratan basılı reklam afişleri incelenecektir. Postmodernizmin fikir öncilerinden Lyotard ve Baudrillard'in döneme dair öne çıkardıkları unsurlar ile postmodern sanat akımlarının özellikleri kriterler olarak ele alınarak içerik analizi yöntemiyle incelenecektir.

\section{Postmodernist söylem ve kuramsal çerçevesi}

Postmodernite, modernite sonrası başlayan döneme, Aydınlanma çağının bitimiyle var olan, jeopolitik bir düzene işaret eder. Postmodernizm ise sanat akımı ve düşünce şekli olarak postmodernite döneminin başında aktif olmuştur (Odabaşı, 2012: 24). Postmodernizm kavramı, kültür ve düşünce evreninin tüm alanlarını içine alan, bütünsel bir yeni aşama ya da durumu anlatmak için kullanılır (Şaylan, 2009: 53).

Odabaşı, Postmodern Pazarlama adlı kitabında postmodernizm söylemini şöyle özetler (Odabaş1, 2012: 25, 26):

- Genel gerçeklik taşıyan düşüncelerin reddedilmesi,

- Bilgi literatürlerinde, dil oyunlarında, bilim dünyasında çoğulculuğun ve parçalanmanın kabul edilmesi,

- Farklı ve çeşitli olma halinin vurgulanıp benimsenmesi,

- Dilsel dönüşümün hakikat, gerçeklik ve doğruluk anlayışlarının tartışılmasına yol açmasıyla hayata geçirilmesi,

- Salt değer anlayışı yerini, yoruma dayalı seçeneklerin alması,

- Gerçeğin sonsuz kez yorumlanması,

- Belirlenmiş zaman ve marka sözcüklerini kullanmak yerine gerçekliğin kendi bütünlüğünü, özerkliği içinde anlamaya çalışması,

- Dini, insanı ruh ve beden olarak ikiye bölen anlayışlarla, hoşgörüyle hesaplaşması,

- Önemli olanın doğrunun ne olduğu değil nasıl olduğu olması, 
Kılıç Taran, B. (2017). Tüketim toplumunda postmodern sanat akımlarının reklamdaki yansımaları. International Journal of Social Sciences and Education Research, 3(2), 434-447.

- Genel kabul gören herşeye karşı çıkışta olduğu gibi ahlaksal anlayışlar ve ilkelerin de geçersiz olması; herşeyin zamanın gereklerine göre şekillenmesidir.

Bütün bu özellikler gösteriyor ki postmodern düşünce; düzen ve kaosun bir arada bulunabileceği, düzensizliğin içinden düzenin doğabileceğini, kabullenilmiş ya da inanılmış değer yargıları dahil hayata dair her şeyi dağıtabileceği ve tek doğrunun varlığını inkar etmeyi savunur (Odabaş1, 2012: 26). Postmodernlikten söz etmek, örgütleyici ilkelere sahip yeni bir çağ değişikliğinden, diğer bir deyişle modernlikten kopuşu ileri sürmek demektir. Postmodern kültürün önemli iki boyutu Jeameson'ın tespitine göre: Gerçekliğin imajlara dönüşmesi ve zamanın bir dizi ebedi şimdiler halinde parçalara ayrılmasıdır (Featherstone, 1991: 25).

Postmodernlik gerçek ile görünüş arasındaki yorum farkını ortadan kaldırmaya çalışır. Öznenin dışındadır ve ondan bağımsız bir şekilde var olabilen objektif bir gerçeğin varlığını kabul etmemektedir. Modern çağın aksine gerçeği ve gerçekliği sorgulayan postmodern çağda bilgi geleneksel kabullerdeki gerçeğin karşıllı̆ 1 değildir, gerçek hep yeniden üretilir. Postmodernler, gerçekliğin var olup olmadığını incelemezler. Onlara göre gerçek, insanların ele aldıkları konulara göre kendilerinin oluşturdukları bir kavramdır (Özkiraz, 2003: 137, 138). Dolayısıyla bilgi görecelidir. Gerçek yerine yorumlamalar vardır ve insan doğruya algılamayla ulaşır.

Postmodernizme ilişkin fikirlerin öncüleri, sosyal kuramda çalışmaları başlatanlar Fransız filozofları Lyotard ve Baudrillard'dır (Smith, 2007: 294).

Lyotard için kapitalizm ve onun ideolojisini sorgulamadığı söylenebilir ama postmodern felsefenin en önemli teorisyenlerinden biridir (Şaylan, 2009: 52). Bir tesadüf sonucu yazdığını söylediği 'Postmodern Durum' adlı eseri, temel eseri olmuştur (Lyotard, 1990: 8). Lyotard'ın bu kitaptaki iddiası 'ideolojilerin ve üst-söylemlerin/ anlatıların' sonuna gelindiğidir (Akay, 2010: 31). Ayrıca Lyotard çalışma hipotezinin postendüstriyel kültürlerin postmodern çağa girdikçe bilginin konumunun değişeceği üzerine olduğunu belirtir. Ona göre, bilgiyi kullananla bilgiyi üretenler arasındaki iliş̧i değişip ticari bir ilişki haline gelmiş̧ir (Lyotard, 1990: 10,11). Postmodern çağ, bilim, teknoloji, karmaşık idari sistemler ve bilgisayarlar aracılığıyla üretimin esas güç olduğu bir süreçtir. Bu değişimle bir zamanlar toplumsal yaşamı canlandıran hayali, ütopik, hümanistik söylemler otoritelerini yitirdiler. Bu durumu Lyotard 'büyük anlatıların çöküşü' olarak değerlendirmiştir. İnsanların çoğu artık ne bilim ve aklın toplum sorunlarını çözümleyebileceğini ya da daha iyi bir dünya kurmamıza yardımcı olabileceğine; ne de bütün bilgi ve deneyimin birleştirilip tek bir kuram ya da dünya görüşü kurabileceğimize inanır (Smith, 2007: 295).

Modern dünyanın kodlarını çok iyi çözmüş olarak tanımlanan Baudrillard ise, insanlığın durumuna isyan eden postmodernizmin en önemli filozoflarındandır. Simülasyon, sanal, hiper gerçeklik, ilüzyon gibi kavramlarla çağın ruhsuzluğunu anlamaya çalışmıştır. Toplumun artık maddi malların kullanım değerleriyle değişimine dayanmadığını; toplumun 'şifre' olarak adlandırdığı şey içinde basmakalıp ve değişken manalar taşıyan kodlar ve sembollerle; metalarla alakadar olduğu iddiasındadır. Ona göre, tüketim toplumu, insanlarının kimliklerini doğrulama çabasında olduğu, bunu paylaşılan işaretler sisteminden satın aldıkları ve tüketmekten büyük haz duyduğu bir toplumdur (Smith, 2007: 296). Baudrillard, Tüketim Toplumu adlı kitabında bu konuyla alakalı "Dolaşım, satın alma, satış, farklılaşmış mallar ve nesneler/göstergelerin sahiplenilişi günümüzde dilimizi, şifremizi tüm toplumun iletişime geçmek ve konuşmak için kullandığı şeyi oluşturur. İşte bu tüketimin yapısı, tüketimin dilidir; bireysel ihtiyaçlar ve hazlar bu dile bağlı olarak söz etkilerinden ibarettir" demektedir (Baudrillard, 2010: 92, 93). 
Kilıç Taran, B. (2017). The reflections of postmodern art movements on advertising in consumer society. International Journal of Social Sciences and Education Research, 3(2), 434-447.

Baudrillard'a göre, 'kültür' ile 'gerçek' arasındaki ve 'işaret' ile 'işaretleşmiş şey' arasındaki ayrımların bir önemi yoktur. İşaret ve sembollerin, altında yatan gerçeklikleri gizlediklerini ya da gerçekliğin üzerinde yapay bir dış görünüş sağladıklarını ileri sürer. Her yerde gerçeklik yerine neo-gerçeklik kullanılmaktadır (Smith, 2007: 297). Postmodern toplumda 'gerçek' kavramı 'taklit' kavramının gölgesinde kalmıştır. Bu düzeni anlatmak için simülakr (taklit) ve simülasyon (benzeşim/ taslama) kavramlarından yararlanmıştır. Simülakr gerçeğin yerini alan kopyanın kopyasidir.

\section{Tüketim toplumunda postmodernizm ve postmodern sanat akımları}

Postmodern söylemin ortaya çıkışı tüketim toplumu ve kültürü ile yakından ilintilidir. Tüketim toplumu kapitalizmin ileri aşamasında oluşan toplumsal bir modeldir. Toplumsal hayat yeniden inşa edilirken, yeni bir tüketim kültürünün oluşmasına yol açmıştır. Tüketim toplumunda kapsam ve içerik bakımından meta üretimi ileri boyutlara ulaşmıştır. Bu durumda sermaye birikimi için kütlesel tüketimin sağlanması gerekmektedir. Dolayısıyla kapitalizmin ileri süreçlerinde tüketim toplumu ve bu topluma özgü bir tüketim kültürünün oluştuğu söylenebilir. İnsanın tüketerek kendi özünü bulduğu kültüre tüketim kültürü demek mümkündür. Tüketim kültürü, sembol ya da imaj tüketiminin, fiziksel tüketimin yerini alıp insanın toplumdaki yerini ve diğer bireylerle ilişkilerini belirleyen en önemli değişken haline geldiği kültürel bir pencere olarak düşünülebilir (Şaylan, 2009: 42).

Günümüz kullanımında tüketime yüklenen anlam, satın almak, sahip olmak ya da kullanmanın ötesinde; tüketiciliğ in kişiselleştirildiğidir. Tüketici sihirli sistem tarafından kandırılmanın ötesinde bir rol üstlenmektedir (Mcrobbie, 2013: 57). Dolayısıyla postmodern insan, metalar tarafindan sarılmış, tüketime bağlı statüleri kabul eden yeni bir insandır.

Postmodernizmin ilk kaynağı sanattır. 1960'lı yıllarda en önemli çıkış sebebi, kurumsallaşmış sanata, galerilere ve müzelere, eleştirel akademik beğeni düzenine ve sınırları belirlenmiş sanat eserlerinin seyirlik nesneler olarak yüceltilmesine karşı ayaklanmadır. Bu başkaldırıyla gündelik hayat ve sanat arasındaki engeller ortadan kalkacak, sanatın müzedeki üst-nesne algısı sonlanacaktır (Featherstone, 1991: 76).

Sanatlar bağlamında postmodernizmle ilişkilendirilebilen temel özellikler, sanat ve gündelik hayat arasındaki sınırın silinişi; yüksek kitle kültürü/popüler kültür arasındaki hiyerarşik ayrımın çöküşü; sanat üreticisinin özgünlüğünün/dehasının gözden düşüşü; parodi, pastiş, ironi ve kültürün yüzeyselleştirilmesi ve sanatın ancak yinelemeden ibaret olabileceği varsayımıdır (Featherstone, 1991: 28).

Postmodernizmdeki en temel ve kitlelerce kabul edilen sanat akımları Pop Art ve Kavramsal Sanattır.

Pop Art'ın özelliklerini sanatın öncülerinden Richard Hamilton şöyle sıralamıştır (Farthing, 2012: 484): Popüler -kitleler için tasarlanmış-, geçici -kısa süreli çözümler-, atılabilir, düşük bütçeli, toplu üretilmiş, genç - genlere yönelik, zekice, seksi, reklam hileli, çarpıcı, şirket ürünü.

Pop, tüketim kültürü ve reklamı adeta yüceltir, imgeleri yüksek kültür/alt kültür ayrımı yapmaksızın ele alır. Bu ayrımı hazır imgelerden yararlanarak yok eden pop sanatçıları; yeni bir imge yaratmadan var olan imgeler dağarcığından tüketime yönelen dünyanın yansımalarını sunmuşlardır (Antmen, 2010: 162). 
Kılıç Taran, B. (2017). Tüketim toplumunda postmodern sanat akımlarının reklamdaki yansımaları. International Journal of Social Sciences and Education Research, 3(2), 434-447.

Kavramsal sanat herhangi bir nesneyi ya da eylemin sanat olarak sunulması; yaratıc1lik olgusunun tanımını değiştirmiş, sanatın üstün yeteneğe dayatılması gerektiği mantığını sarsmış ve sanatsal beğeniyi şekillendiren etkenleri düşünsel bir deneyimin önem kazanmasına öncülük etmiştir (Antmen, 2010:194). Aynı zamanda sanat yapıtının meta olarak görülmesine de tepkidir (Farthing, 2012: 501).

\section{Tüketim toplumunda postmodern sanat akımı ögelerini içeren reklam örnekleri}

Tüketim toplumunda yeni olana doğru bir arzu yaratılmaktadır (Kuşay ve Akbayır, 2015: 141). $\mathrm{Bu}$ arzu, reklam sayesinde tüketiciyle buluşur. "Reklam, tüketici ile markayı buluşturan, tüketicinin markanın bilincine varmasını sağlayan önemli bir unsurdur. Reklam yoluyla tüketici malın yaptığı işi ve sağladığı yararları anlar, gördüğü, duyduğu ve okuduğu bilgi kaynakları sonucu ürünün vaatlerine inanır ve harekete geçerek alış anında o markayı takip eder.” (Ertike, 2010: 21, 22).

Tüketim kültürünün bir parçası olan reklamlar, malın kullanım değerinin yanı sıra ona yaşam tarzı, sembolik değerler ve hazlar da yükleyerek; anlam, kimlik ve prestij sistemi oluşturmaktadır ve en önemlisi tüketiciye ihtiyaçlarını oluşturduğu bu değer sistemleri üzerinde kurgulanmaktadır (Çabuk, 2012: 43). Böylece reklamda ürün, imajın arkasında kalmaktadır. Bu temel değişim, postmodern reklamlarda izleyicinin yoruma davet edilmesi ve anlamlandırma gücünün tüketiciye ait olmasının bir sonucu olarak ifade edilebilir (Odabaşı, 2012: 162).

Çalışma kapsamında ele alınan reklam örnekleri 'Reklamda Pop Art Sanat Akımının Etkileri' ve 'Reklamda Kavramsal Sanat Akımının Etkileri' olmak üzere iki ayrı başlık altında gösterilmektedir. Ele alınan örnekler, Postmodern sanat öğeleri (kaos, parçalara ayırma, gündelik hayat, pop, çizgi karakterler, metafor, yorumlanabilir, seri üretim), Lyotard'ın postmodern kriterleri (Büyük anlatıların çöküşü - küçük anlatıların tercih edilmesi gerekliliği, büyük alanın parçalara ayrılması, ironi-eleştirel yaklaşım-dolaylı anlatım) ve Baudrillard'ın postmodern kriterleri (İşaret ve sembollerle gerçeğin gizlenmesi - yapay dış görünüm, simülakr (taklit) ve simülasyon (benzeşim) - gerçek olanı taklitle benzeştirerek yeni bir imaj oluşturma) bağlamında incelenmektedir.

\subsection{Reklamda Pop Art Sanat Akımınin etkileri}

Resim 1. KitchenAid mutfak aletleri basılı reklam görseli

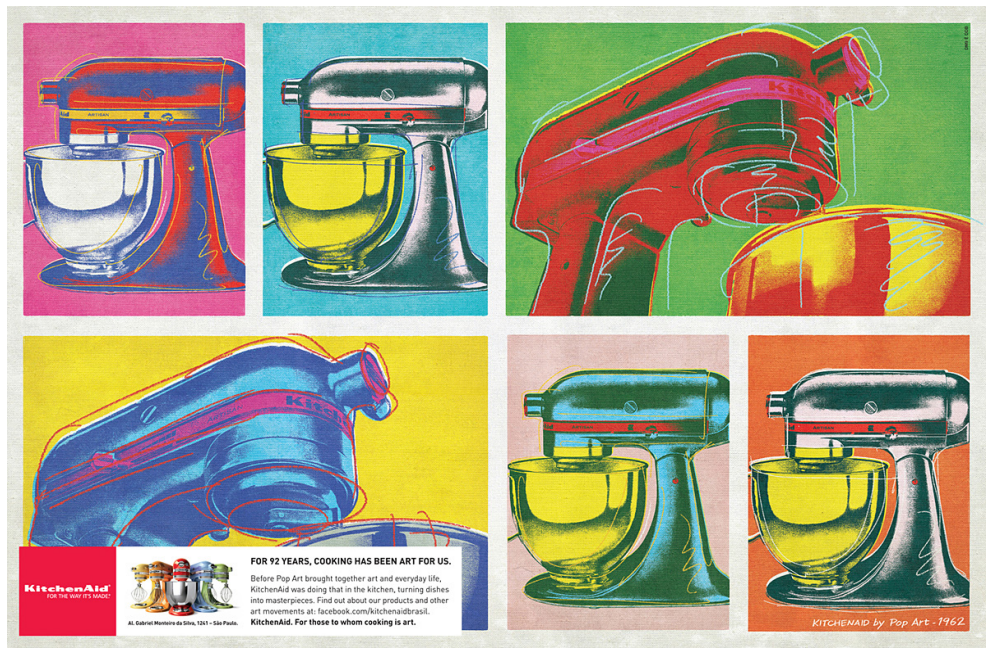

Kaynak: advertolog.com/whirlpool/print-outdoor/pop-art-14707155/, 15/09/2016 
Kilıç Taran, B. (2017). The reflections of postmodern art movements on advertising in consumer society. International Journal of Social Sciences and Education Research, 3(2), 434-447.

Resim 1'de KitchenAid Mutfak Aletleri'nin yararlandığı bir reklam görseli yer almaktadır. Görselin sağ alt kısmında adeta imza forumunda "KITCHENAID by Pop Art 1962" yazmaktadır. Sol alt köşedeki açıklayıcı metinde ise: "92 yll boyunca yemek bizim için sanat olmuştur. Pop Art'ın sanatı ve gündelik hatayı birleştirmesinden önce, KitchenAid yemekleri şahesere dönüştürüyordu. Ürünlerimiz ve diğer sanat hareketleriyle alakalı bilgi alın. KitchenAid: Sahip olanlar için yemek bir sanattır."

Bu görselden yola çıkarak tıpkı Pop Art mantığındaki gibi ürünün günlük hayatı sanatla kavuşturma amacı güttüğü düşünülmektedir.

PopArt'ın öncülerinden Andy Warhol'un Marilyn isimli eserinde olduğu gibi, bu örnekte de reklamın parçalara bölünmüş, tekrara yer verilmiş ve canlı renkler kullanılarak, çizgi karakter görünümü oluşturulduğu görülmektedir. Renklerle izleyicide pozitif hisler ve enerji uyandırması hedeflenmiştir. Açıklama metninin yanında yer alan ürünün gerçek görüntüleriyle de 'gerçek' ve 'hayal' ilişkisi kurulmaktadır.

Resim 2. Umbro basıl1 reklam görseli

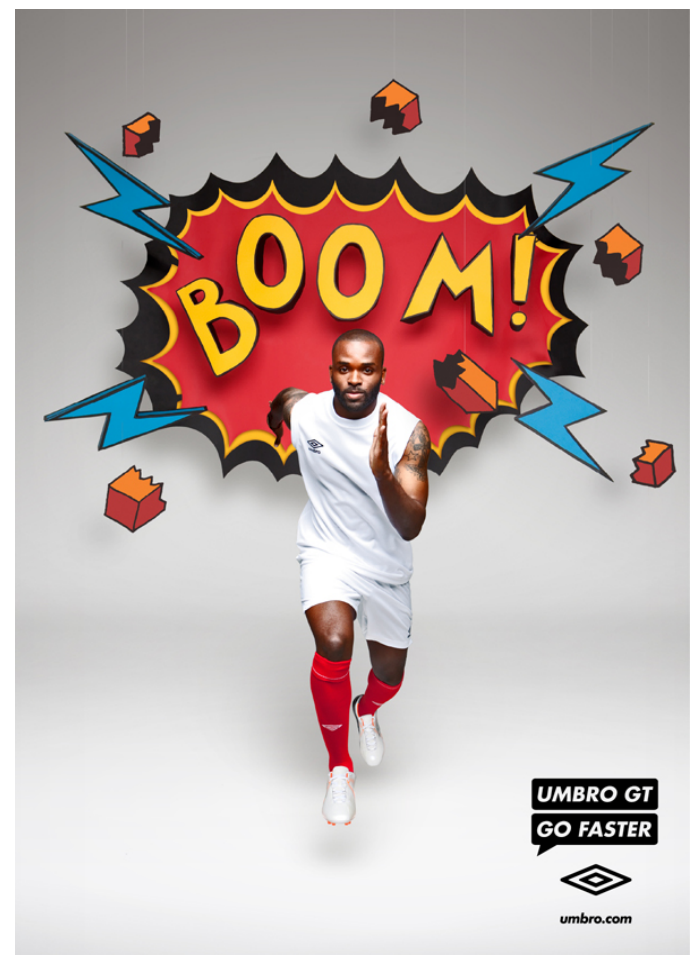

Kaynak: thedrum.com/news/2010/07/20/darren-bent-pop-art-and-love-umbros-new-bootsads, 09/09/2016.

Reklamda açıklayıcı metin kullanılmayıp, görsel malzemeye ek olarak sadece slogana yer verilmiştir. Slogan, çizgi romanlardaki konuşma balonunun yeniden yorumlanmış haliyle, logoyu konuşturur biçimde alana oturtulmuştur: "Umbro GT hızlı gider"

Görsel sloganı destekler nitelikte dikkati çekmektedir. Çizgi karakterlerle yapılmış patlama efekti ve mesajı kuvvetlendirici tipografik öge konumlandırılmıştır. Reklamda yırtılan patlayan alan, etrafa saçılan tuğlalardan anlaşıldığı üzere duvardır. Reklamda, baştan aşağı Umbro ürünleriyle giyinmiş, hızlı koşabilme yeteneğiyle nam salmış siyahi bir futbolcu tercih edilirken sloganın etkisi kat be kat kuvvetlendirilmiştir. 
Kılıç Taran, B. (2017). Tüketim toplumunda postmodern sanat akımlarının reklamdaki yansımaları. International Journal of Social Sciences and Education Research, 3(2), 434-447.

Resim 3. Ray-Ban Rare Prints reklam kampanya görselleri
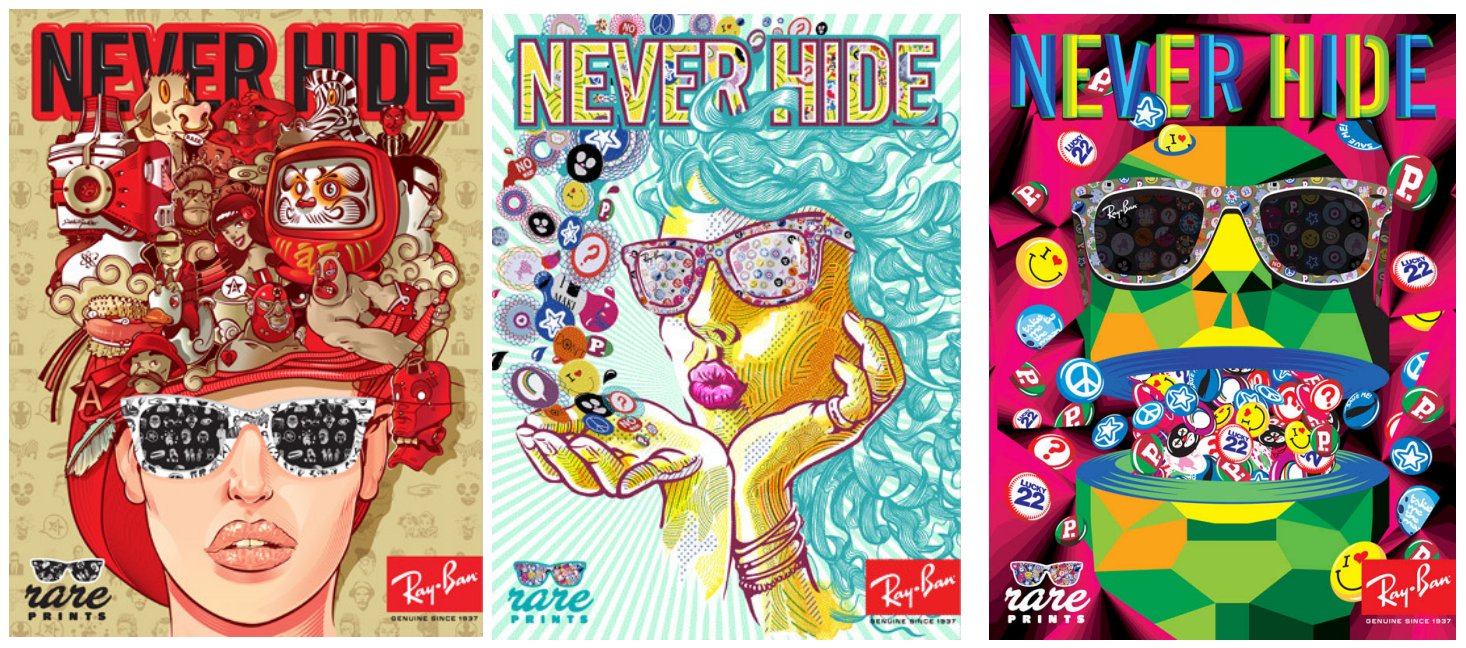

Kaynak: adsoftheworld.com/campaign/rayban-cutwater-10-2010_0, 02/10/2016

Resim 4. Ray Ban Colorize reklam kampanya görselleri

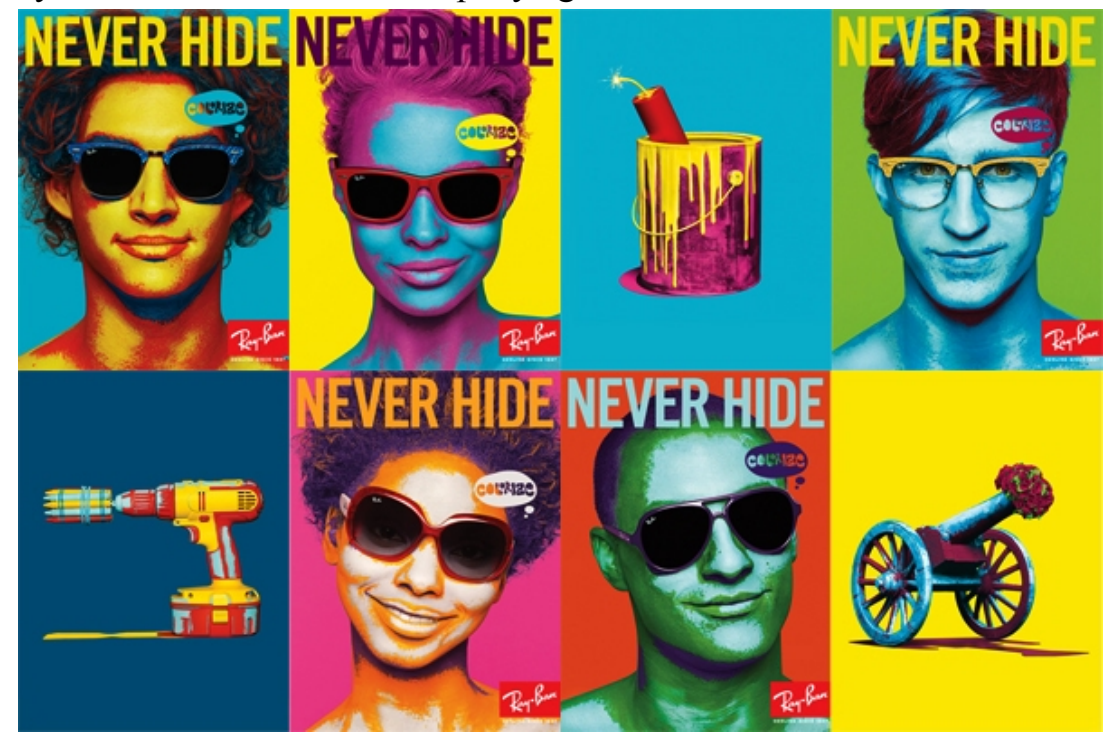

Kaynak: es.paperblog.com/ap-ray-ban-pop-art-1356826/, 02/10/2016

Gözlük markası, Rare Prints (Resim 3) ve Colorize (Resim 4) model gözlüklerini aynı sloganla ve pop art sanatını kullanarak reklam kampanyası yapmayı tercih etmiştir. Ortak slogan NEVER HIDE (asla gizleme)' dir. Görseller, sloganı güçlü renklerle canlı tutmaktadır. Hedef kitleleri cesur olabilenler ve tabii ki gençlerdir.

Görsel 3'de posterin genel dokusunu veren desenler, gözlük çerçevelerini kaplayan desenlerdir. Kampanya görsellerine dinamizm, devinim hakimdir. Görseller fazlaca parçalanmış ve dağıtılmış pop kültür ögelerinin kolajlanmasıyla oluşturulmuştur. Portreler ilüstrasyonla oluşturulmuştur.

Görsel 4'de ise gözlüklere karakterini renkli çerçeveler verilir ve bu rengarenk görünüm, pop art sanatıyla öne çıkartılır. Bölünmüş alanlar zaman zaman ikili gruplar olarak da kullanılmıştır. Gözlükler bu sefer gerçek portre fotoğraflar üzerinde yapılan oynamalarla gösterilmiştir. Portrede 
Kilıç Taran, B. (2017). The reflections of postmodern art movements on advertising in consumer society. International Journal of Social Sciences and Education Research, 3(2), 434-447.

üst giysi detayı bulunmamaktadır ve dolayısıyla dikkat tek giysi olan gözlük çerçevesine çekilmiştir. Bu dikkati akabinde portrelerdeki yüz ifadeleri takip eder. Memnun ifadeler, renklerin psikolojik etkisiyle izleyicide hayal gücünü aktive eder. Üç bölmede kullanılan boya kovasındaki patlayıc1, ucunda renkli kalemlerin sarılı olduğu matkap ve yine etrafı boyamaya hazır top arabası renklere yapılan vurguyu arttırmakla beraber; bu renk patlamasının bir gözlük çerçevesiyle çok hızlı bir şekilde yapılabileceği izleyiciye verilen mesajlar arasındadır.

\subsection{Reklamda kavramsal sanat akımınin etkileri}

Resim 5. Audi reklam kampanya görseli

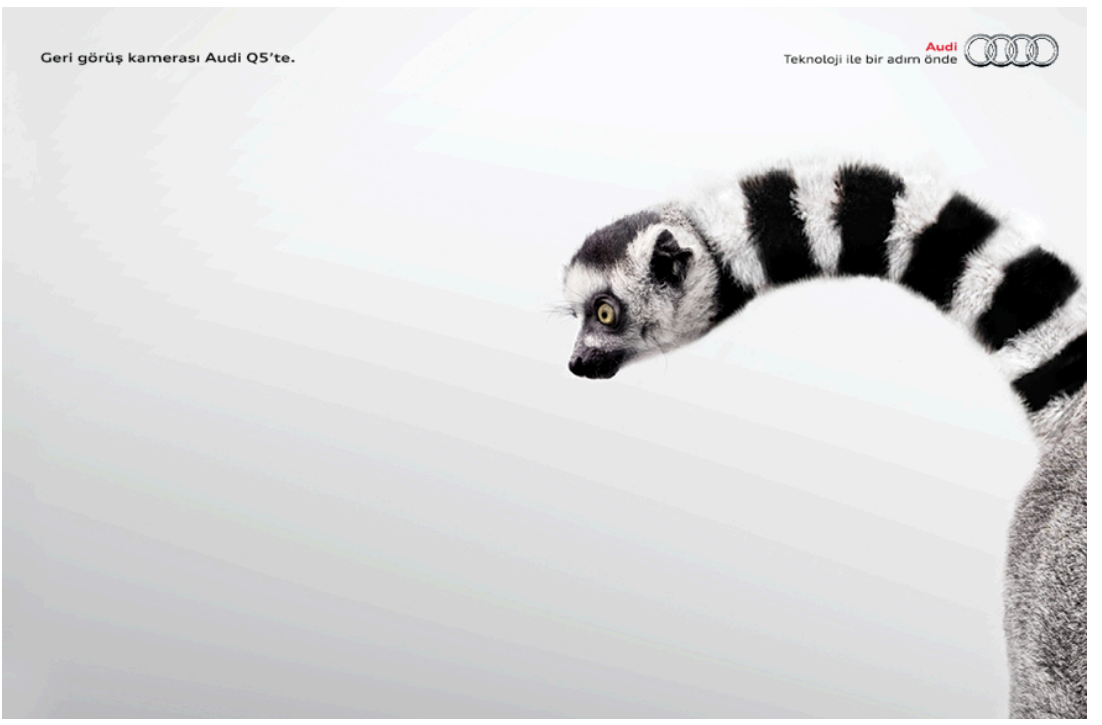

Kaynak: gutewerbung.net/audi-q5-rearview-camera-lemur/, 12/09/2016

Resim 5'deki reklamda kuyruklu bir hayvanın (lemurun) profilden bir kesiti kullanılmıştır. Kesitte hayvanın etkin biçimde kuyruğu gözükmektedir, fakat doğaya aykırı biçimde hayvanın kafası kuyruğunun ucuna montajlanmıştır. Zeminde açık bir renk kullanılarak görsel daha belirgin kılınmıştır. Reklamdaki boş alan, lemurun bakışlarıyla doldurulmuştur.

Logo sağ üst köşede konumlanırken, lemurun nereye neden baktığı anlamlandırılamayan boşluğun üstüne bilgilendirme metni konulmuştur: "Geri görüş kamerası Audi Q5'te". Yapılan metafor, metinle anlam bulmaktadır. Bu reklamın, bir otomobil markasının modelinde öne çıkarmak istediği detayı vurgulamak için tasarlandığı düşünülmüştür.

Resim 6'da da yine seyrederken anlamaya çalıştığımız bir reklam çalışması bulunmaktadır. Fon rengi mat ve tek renkte tutularak görsel ön planda tutulmuştur. Oluşturulan görsel ilk bakışta bir çantadır; fakat oldukça yağlı ve kilolu bir erkeğin göbeğinden yapılmış bir çanta. Çantanın sapları bir uçtan diğer uca, adeta pantolon askısı gibi, içine atılacak eşyanın oranına göre ayarlanabilen askılarla desteklenmiştir. Görseli anlamlandırabilmek için sağ alt köşede marka ile yan yana konumlandırılan slogana bakmak yeterlidir: "Fazlalıklarını taşıma" - Gerda Plates. 
Kılıç Taran, B. (2017). Tüketim toplumunda postmodern sanat akımlarının reklamdaki yansımaları. International Journal of Social Sciences and Education Research, 3(2), 434-447.

Resim 6. Gerda Plates reklam kampanya görseli

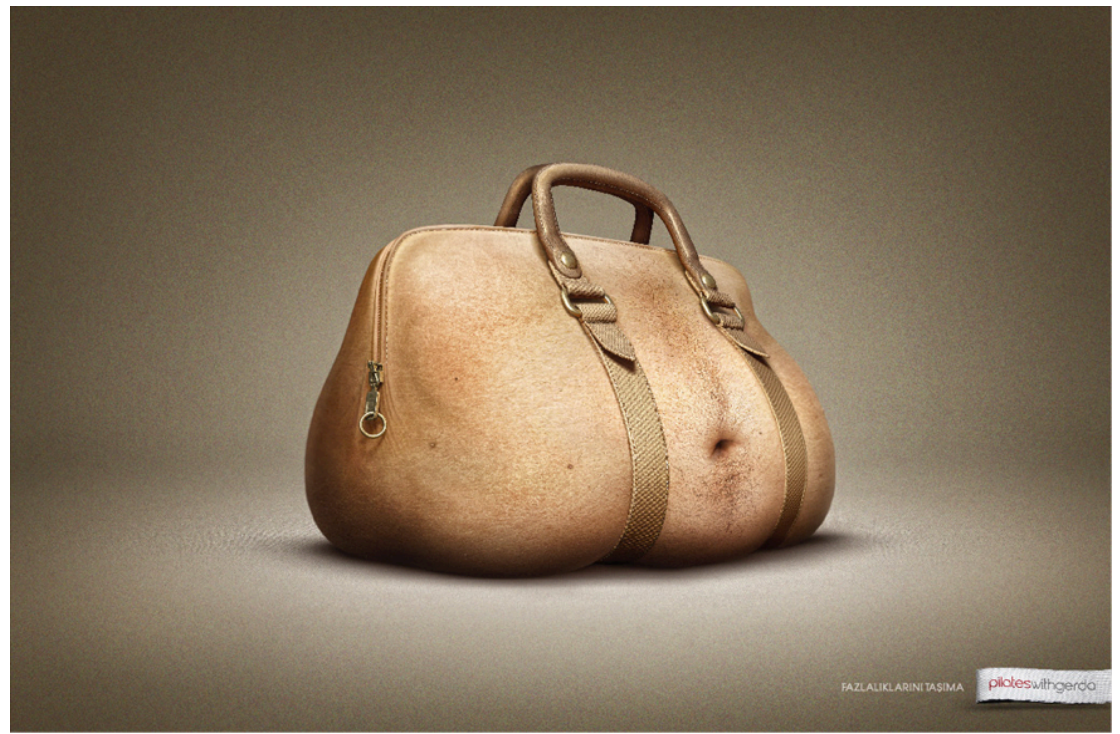

Kaynak: reklamin-iyisi.blogspot.com.tr/2011/12/yuku-fazla-olanlara-pilates-with-gerda.html, 26/09/2016

Resim 7. Faber Castell Real Colors reklam kampanya görselleri
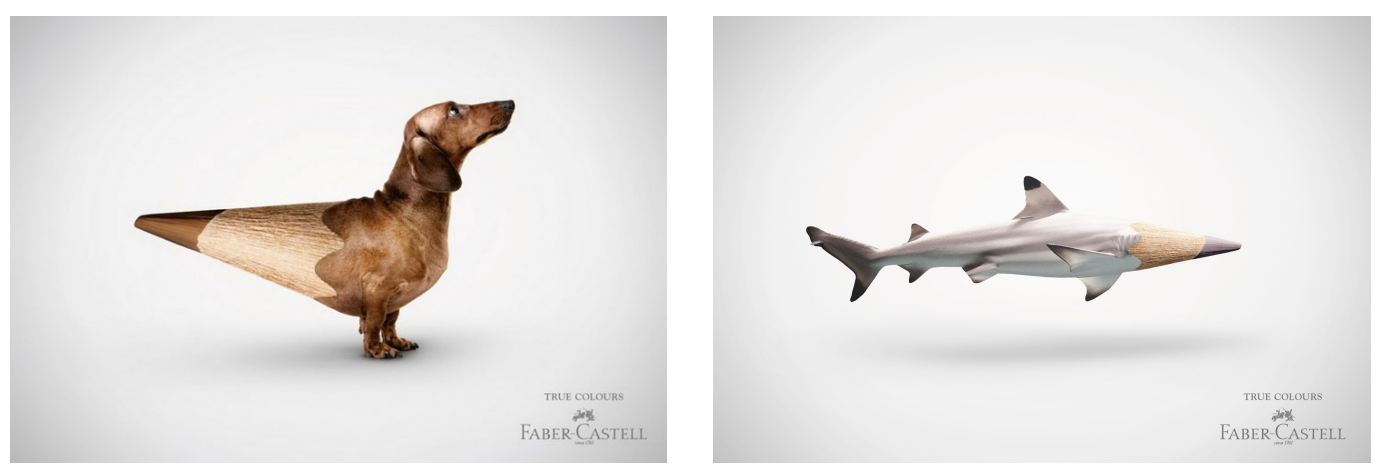

Kaynak: adsoftheworld.com/media/print/fabercastell_dachshund, adsoftheworld.com/media/print/fabercastell_shark, 29/09/2016

Kavramsal sanat akımına dair yukarıda bahsi geçen reklamlardan da alışık olunduğu üzere zemin tek ve açık renk kullanılarak ilgi görsele çekilmiş. Faber Castell kalemleri canlı varlıklarla eşleştirmiştir. Okuma alışkanlığımızdan ötürü de gözümüzün en son baktığı nokta olan sağ alt köşeye marka ve hemen üstüne "gerçek renkler" sloganı yerleştirilmiştir.

Diğer reklamların aksine marka, logosunu kullanmamayı tercih etmiştir. Yüz küsür yıllık geçmişiyle Coca Cola bilinen bir marka olmanın avantajını, reklam kampanyasında sadece ambalajlarında uyguladığ 1 dalga formunu kullanarak ortaya koymuştur. Formun eşittiri, zihinlerde markanın kendisidir. Metin ve logo kullanmamasındaki cesaret köklü bir dünya markası olmasından ileri gelmektedir. Kampanya görselleri bu dalga formuyla iki eşit parçaya ayrılır ve bu parçalar dünyanın çeşitli bölgelerinden iki insan portresi kullanılarak tamamlanır. İki insan, Coca Cola'nın birleştirici gücüyle tek insan olur. Markanın geçmişten günümüze süre gelen reklamlarında aşıla- 
Kilıç Taran, B. (2017). The reflections of postmodern art movements on advertising in consumer society. International Journal of Social Sciences and Education Research, 3(2), 434-447.

nan mutluluk ifadesi görseli bütünleştirmiştir. Firma, kampanyayı "küçük dünya" başlığıyla piyasaya sürmüştür. Dünya Coca Cola'nın dağıttığı sevgiyle birdir, küçücüktür. Çünkü sevgi, mutluluk büyüktür.

Resim 8. Coca Cola Küçük Dünya reklam kampanya görselleri

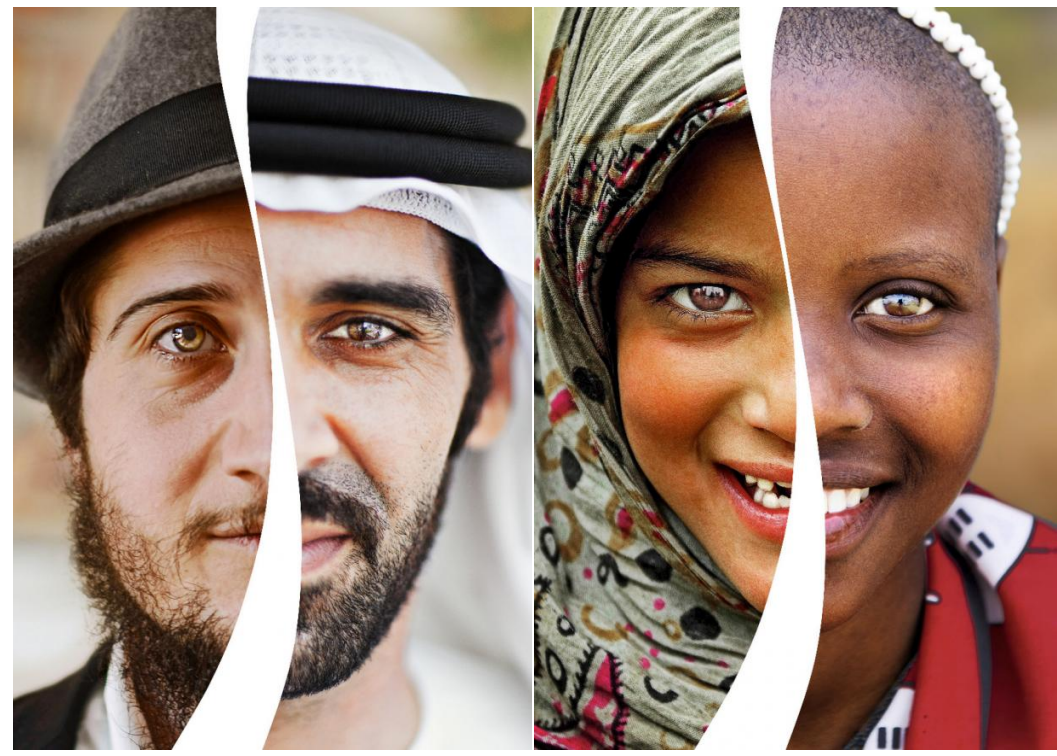

Kaynak: theinspirationroom.com/daily/2013/coca-cola-small-world-in-print/, 22/09/2016

\section{Sonuc}

Postmodernizmle birlikte yüksek sanat ve gündelik hayat arasındaki sınırlar kopmuş, seçkincilik dışlanmıştır. Sanatın her alanında katı kuralların yıkılmasıyla, oluşan kültür metaların kullanım değerinin değişmesine yol açmıştır ve sonucunda postmodern dönemde metalar göstergeler haline gelmiştir. Yani insanlar göstergeler, imajlar ve simülasyonlarla gerçek olmayan bir tüketim dünyasının içine düşmüşlerdir. Bu sahte yaşamın devamlılık kaynağı, yaratılan mutluluktur.

Reklamın görevi ise, pazarlanan ürün ya da hizmetin tüketildiğinde mutluluk hissini yaratacak olmasıdır. Reklamla oluşturulan simülakr ağı bireyin bakış açısını belirlemektedir ve bu yaratım süreci sanatla ilintilidir. Çalışmada ele alınan örnekler kapsamında tüketim toplumunda reklam aracılığıyla hedef kitleyi etkilemek için sanata başvurulduğu ve postmodern sanat akımlarının da etkili biçimde kullanıldığı görülmüştür.

İncelenen postmodern sanat akımı kullanılarak tasarlanmış reklam görselleri ışığında;

Pop art reklamlarında oluşturulan ortak dilin canlı renk kullanımı, hareket-devinim hissi, çizgi karakterlerin fazlalığı, tekrar ve kaosla oluşturulduğu gözlemlenmiştir. Kavramsal sanatla oluşturulanlarda ise bu dil, çoğunlukla metafor kullanımına yer verilerek, birbirinden ayrı bütünün parçaları uygun forma getirilip bir bütün görünümüne ulaştırılarak sağlanmıştır. Genellikle sloganlar, oluşturulan görseli anlamlandırma noktasında önemli rol üstlenmişlerdir.

Kuramsal çerçeve göz önünde bulundurulduğunda;

- Sanat reklamlarda kullanılarak, yani günlük hayata indirgenerek yüksek kültüre karşı çıkılmiştır.

- İşaret ve sembollerle yeni gerçeklik algısı oluşturulmuştur. 
Kılıç Taran, B. (2017). Tüketim toplumunda postmodern sanat akımlarının reklamdaki yansımaları. International Journal of Social Sciences and Education Research, 3(2), 434-447.

- Büyük alanlar, küçük ve birbirinden farklı parçalardan oluşturulmuştur.

- Gerçek olanı taklit ve benzeşimle yoruma açık hale getirilmiştir.

- Dolaylı anlatıma yer verilmiştir.

Dolayısıyla çalışmanın, postmodern sanat akımlarıyla oluşturulan reklamların, postmodern sanatın temel kriterlerini ve dönemin fikir babalarından J. F. Lyotard ve J. Baudrillard'ın öne çıkardığı unsurları fazlasıyla yansıttığı görülmektedir.

\section{Kaynakça}

Akay, A. (2010). Postmodernizmin ABC'si. İstanbul: Say Yayınları

Antmen, A. (2010). 20. Yüzyıl Batı Sanatında Akımlar. İstanbul: Sel Yayınları

Baudrillard, J. (2010). Tüketim Toplumu. Çev. Deliceçaylı, H., Keskin, F., İstanbul: Ayrıntı Yayınları

Çabuk, D. (2012). Cosmopolitan Reklamlarında Anlam Yapıları ve İdeoloji. Global Media Journal, Yeditepe Üniversitesi. 3(5), 40-60 .

Ertike, A. S. (2010). Reklam. Ankara: Detay Yayıncıllk

Farthing, S. (2012). Sanatın Tüm Öyküsü. Çev. Aldoğan, G., Candil Çulcu, F., Çin: Hayalperest Yayınevi

Featherstone, M. (1991). Postmodernizm ve Tüketim Kültürü. İstanbul: Ayrıntı Yayınları

Kuşay Y., Akbayır Z. (2015, Haziran). Dijital Oyunlar ile Tüketime Yolculuk: "Öğrenme Yaklaşımı Açısından Çocuk Kullanıcılara Yönelik Bir Araştırma”, Akdeniz İletişim Dergisi, 23, 135-154.

Lyotard, J. F. (1990). Postmodern Durum. Çev. Çiğdem A., İstanbul: Arı Yayınları

Mcrobbie, A. (2013). Postmodernizm ve Popüler Kültür. Çev. Özdel, A., İstanbul: Parşömen Yayıncılık

Odabaşı, Y. (2012). Postmodern Pazarlama. İstanbul: MediaCat Kitapları

Özkiraz, A. (2003). Modernleşme Teorileri ve Postmodern Durum. İstanbul: Çizgi Kitapevi Yayınları

Smith, P. (2007). Kültürel Kuram. Çev. Güzelsarı, S., Gündoğdu, İ., İstanbul: Babil Yayınları

Şaylan, G. (2009). Postmodernizm. Ankara: İmge Kitapevi Yayınları

http://adsoftheworld.com/campaign/rayban-cutwater-10-2010_0, Erişim Tarihi: 02 Ekim 2016

http://adsoftheworld.com/media/print/fabercastell_dachshund, Erişim Tarihi: 29 Eylül 2016

http://adsoftheworld.com/media/print/fabercastell_shark, Erişim Tarihi: 29 Eylül 2016

http://www.advertolog.com/whirlpool/print-outdoor/pop-art-14707155/, Erişim Tarihi: 15 Eylül 2016

http://es.paperblog.com/ap-ray-ban-pop-art-1356826/, Erişim Tarihi: 02 Ekim 2016

http://www.gutewerbung.net/audi-q5-rearview-camera-lemur/, Erişim Tarihi: 12 Eylül 2016

http://reklamin-iyisi.blogspot.com.tr/2011/12/yuku-fazla-olanlara-pilates-with-gerda.html, Erişim Tarihi: 26 Eylül 2016

http://www.thedrum.com/news/2010/07/20/darren-bent-pop-art-and-love-umbros-new-boots-ads， Erişim tarihi: 09 Eylül 2016

http://theinspirationroom.com/daily/2013/coca-cola-small-world-in-print/, Erişim tarihi: 22 Eylül 2016

\section{Extended abstract in English}

Literature: Postmodernity implies the period which started after modernity and a geopolitical order which emerged with the end of the Enlightenment era. And postmodernism became active in the beginning of the postmodernity period as a current of art and a way of thought (Odabaşı, 2012: 24). Postmodern thought defends that order and chaos may coexist, order may rise within 
Kılıç Taran, B. (2017). The reflections of postmodern art movements on advertising in consumer society. International Journal of Social Sciences and Education Research, 3(2), 434-447.

disorder, everything about life including the accepted or believed value judgements may be deconstructed and existence of a single truth may be contested (Odabaş1, 2012: 26). Talking about postmodernity means, arguing for a new epochal change which has its own organising principles, in other words, it means breaking away from modernity. According to Jameson two significant aspects of the postmodern culture are: Transformation of reality into images and breakdown of time into pieces in the form of a sequence of eternal "now"s (Featherstone, 1991: 25).

The pioneers of the ideas about postmodernism were the French philosophers Lyotard and Baudrillard who started their studies in the social theory. The postmodern era is a process where production via science, technology, complex administrative systems and computers constitute the main power. Together with this change, the imaginary, utopian and humanistic discourses which once upon a time revived the social life had lost their authorities. Lyotard evaluated this condition as the "collapse of the grand narratives". The majority of the people now do not believe that neither the science and ration can solve the social problems and can help us to build a better world, nor all knowledge and experience can be united for building a single theory or a world view. And Baudrillard tried to understand the spritlessness of the era together with the help of concepts such as simulation, virtual and hyper-reality and illusion. He argued that now the society is not based on the exchange of the use values of the material goods; but the society is engaged with codes and symbols, with commodities which bear stereotypical and changing meanings in something which he called as the "passwords". According to him, the consumer society is a society where the people are in an effort of affirming their identities, where they buy this from a shared system of signs and where they enjoy a great pleasure by consuming (Smith, 2007: 294-296).

While the social life is reconstructed together with the emergence of the post-modern discourse, it led the formation of a new consumer culture. Consumption culture might be thought as a culture window where the consumption of a symbol or an image replaces physical consumption and becomes the most important variable which determines the position of a person within the society or his/her relationships with the other persons (Şaylan, 2009: 42). The meaning which consumption assumes in today's usage, is individualisation of consumerism beyond buying, owning or using something. The consumer assumes a role beyond being deceived by the magic system. Hence the postmodern human being is a new human being who is wrapped up with commodities and who accepts statuses based on consumption.

The first source of postmodernism is art. The main characteristics which may be connected with postmodernism within the context of arts is the withering of the borders between art and daily life; the collapse of the hierarchic separation among the high mass culture/popular culture; disgrace of the authenticty/genious of the art producer; parodi, pastiche, irony and superficialisation of culture and the assumption that art is nothing but repetition (Featherstone, 1991: 28). The main art currents which are accepted by the masses in postmodernism are the Pop Art and Conceptual Art. Pop almost sublimes consumption culture and advertisement and deals with the images without making any differentiation among high culture/subculture. The pop artists who destroy this distinction by enjoying the ready images present the reflections of a world which tends to consume from among the existing repertory of images without creating a new image (Antmen, 2010: 162). And the conceptual art by presenting any object or act as art has changed the definition of the phenomenon of creativity, has shaken the logic that art must be based upon superior abilities and its influences which shaped the artistic taste has pioneered an 
Kılıç Taran, B. (2017). Tüketim toplumunda postmodern sanat akımlarının reklamdaki yansımaları. International Journal of Social Sciences and Education Research, 3(2), 434-447.

intellectual experience to gain significance (Antmen, 2010:194). It is at the same time a reaction against the understanding which sees art work as a commodity (Farthing, 2012: 501).

Advertisements which are part of the consumption culture form a meaning, identity and prestige system by also loading life style, symbolic values and pleasures upon a commodity, in addition to its use value and most importantly, they fictionalise the consumers over this value system where their needs are constructed (Çabuk, 2012: 43). Thus in the advertisement the product stays behind the image. This basic change may be articulated as the result of the postmodern advertising where the audience is invited for making interpretations and where the power of attributing meanings belongs to the consumer (Odabaş1, 2012: 162).

Methodology: In order to determine the framework of the study, literature survey is used. The data which are obtained as the result of the literature review about the conceptual dimension of postmodernism and postmodern art currents formed the criteria of the study. Within the framework of the proposed criteria, printed advertisement posters which were designed by using postmodern art currents, which create powerful influence and which are selected by random sampling as the imaginative dimension of the consumption culture in the advertisements were examined.

The examples of advertisements which were dealt with under the study are shown under two separate headings, one as the "Influence of Pop Art Current in Advertisement" and the other as "Influence of Conceptual Art Current in Advertisement". The examples which are dealt with were examined within the context of postmodern art elements (chaos, deconstructing into pieces, daily life, pop, and cartoon characters, metaphor, interpretability and mass production), Lyotard's postmodern criteria (collapse of grand narratives - requirement for preferring small narratives, deconstructing the grand space into pieces, irony - critical approach - indirect narrating) and Baudrillard's postmodern criteria (signs and symbols concealing the reality - artificial outer image, simulacra and simulation - forming a new image) by simulating the real with the simulacrum.

Results and Conclusion: Together with postmodernism the borders between high art and daily life were delinked and elitism was excluded. The culture which was formed by the destruction of the rigid rules in all fields of art caused a change in the use values of the commodities and as a result of this in the postmodern era commodities became indicators. Hence the people had fallen into an unreal world of consumption together with images and simulations. The source of sustainability of this fake life is the happiness created.

And the task of advertisement is to imply that when the marketed product or service is consumed it shall create a feeling of happiness. The simulacra network which is formed through advertisement is determining the point of view of the individual and this process of creation is related with art.

Within the scope of the examples that are dealt within the study it was seen that in the consumer society in order to influence the target audience through advertisement art is appealed and postmodern art currents are used effectively.

Under the light of the examined advertisement visual images that were designed by using postmodern art current:

It was observed that the common language in pop art advertisements was formed with the use of colour, feeling of motion-action, redundancy of cartoon characters, and repetition and chaos. 
Kilıç Taran, B. (2017). The reflections of postmodern art movements on advertising in consumer society. International Journal of Social Sciences and Education Research, 3(2), 434-447.

And in those which were formed by conceptual art this language was obtained by giving a place to usage of metaphor, and by providing a wholesome image, in the appropriate form, to the pieces of a whole which are separate from each other. In general, catchwords assumed an important role at the point of giving a meaning to the image created.

When the theoretical framework is taken into consideration:

- By using art in advertisements, thus it being reduced to daily life, high culture had been opposed.

- A new conception of reality was created with signs and symbols.

- Grand spaces were formed with small pieces which are distinct from each other.

- Real is made interpretable with simulacra and simulation.

- Indirect narrating was used.

Thus the study observed that the advertisements which are created with postmodern art currents largely reflected main criteria of postmodern art and the elements which were emphasised by J. F. Lyotard and J. Baudrillard, two masterminds of the era. 